\title{
Contact lenses: new devices for nucleotide delivery in ocular pathologies
}

\author{
Jesús Pintor
}

Received: 25 July 2014 / Accepted: 4 August 2014 / Published online: 20 August 2014

(C) Springer Science+Business Media Dordrecht 2014

\section{Editorial note from the Editor-in-Chief}

The short Commentary that follows illustrates a novel and interesting advance in technology for the treatment of disorders of the eye.

Recently we have presented the idea that common ocular contact lenses may serve as nucleotide delivery systems. Contact lenses can be easily soaked with nucleotides and these nucleotides can be released in a sustained way permitting longer therapeutic effects [1].

The simplicity of the process relies on two main facts. We have been using commercially available contact lenses based on silicon and silicon hydrogels composition. The lenses are loaded by immersion for $8 \mathrm{~h}$ in the desired nucleotide.

The application of this new approach for nucleotide administration is especially suitable for the treatment of ocular surface pathologies, such as dry eye, corneal wound healing or corneal protection against infections [2]. Nevertheless, it is necessary to be aware that this approach might be used also for the treatment of intraocular pathologies where nucleotides have therapeutic actions, such as glaucoma.

Probably one of the best examples for the use of this delivery system is the treatment of dry eye. The use of $\mathrm{P} 2 \mathrm{Y}_{2}$ receptor agonists for the treatment of ocular surface dryness has been proposed since the late ' 90 s [3]. Dry eye is an ocular surface condition that is often characterized by a small production or by a poor quality of tears. This disorder can be reversed by the application of $\mathrm{P} 2 \mathrm{Y}_{2}$ receptor agonists, the most popular one being diuridine tetraphosphate $\left(\mathrm{Up}_{4} \mathrm{U}\right)$ since

J. Pintor $(\bowtie)$

Department Biochemistry, Faculty of Optometry, University Complutense of Madrid, c/Arcos de Jalon 118, 28037 Madrid, Spain e-mail: jpintor@ucm.es it has been commercialised in Japan under the name Diquas ${ }^{\circledR}$ [4]. Nevertheless, increased tear secretion can also be obtained by means of compounds such as ATP, UTP, 2-thioUTP and the dinucleotide $\mathrm{Ap}_{4} \mathrm{~A}$. For all these substances the main problem is that when they are topically applied on the ocular surface they are quickly drained by the canaliculi, limiting their presence on the ocular surface for a maximum of $5 \mathrm{~min}$ [5]. This limits the time they have to produce a sustained action. Indeed, topical application of ATP on the cornea produces a rise in tear production, but the effect only lasts for $90 \mathrm{~min}$ (Fig. 1). In contrast, if we immerse commercial silicon and hydrogel silicon contact lenses in $1 \mathrm{mM}$ ATP for

\section{- Topical application \\ - Contact lens with ATP \\ - Contact lens with UTP}

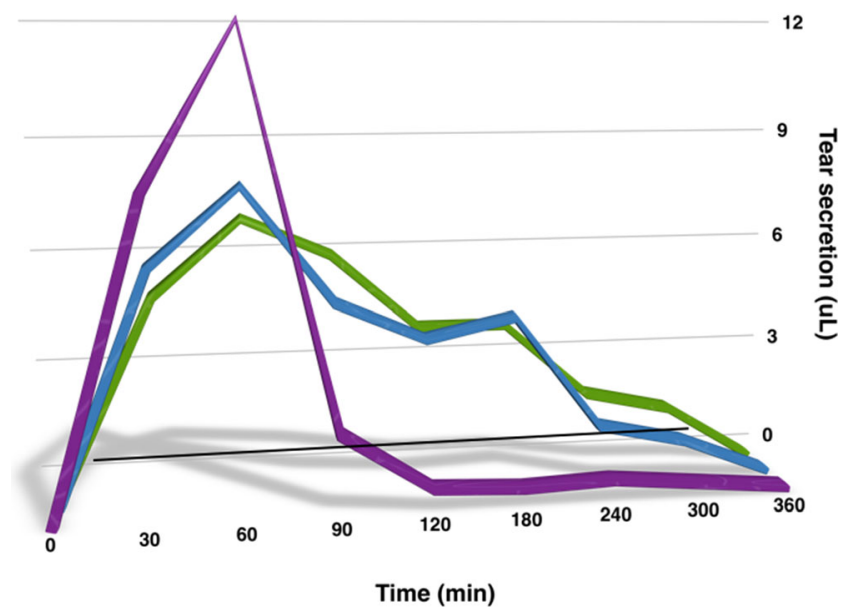

Fig. 1 Tear secretion production elicited by ATP and UTP in New Zealand white rabbits. The effect of a topical application of ATP presents an acute, but short effect on tear secretion. In contrast, the delivery of ATP or UTP from contact lenses produces a sustained release that prolongs tear secretion for up to $6 \mathrm{~h}$ 
$8 \mathrm{~h}$ and then place the lens in the eye (rabbit eye), we get a more persistent release of ATP that concomitantly produces a more sustained effect on tear secretion, as seen in Fig. 1. A similar effect can be obtained when instead of ATP we use UTP, both agonists of the $\mathrm{P}_{2} \mathrm{Y}_{2}$ receptor. Interestingly, the use of the contact lens provides a tear secretion effect that lasts for $6 \mathrm{~h}$ in contrast with the topical application that only lasts for 90 mins.

This example shows how commercially available contact lenses can store and deliver nucleotides such as ATP and how the slow release can help to avoid repetitive topical instillations, for example when Diquas ${ }^{\mathbb{B}}$ is prescribed by the ophthalmologists.

In summary, a good way to deliver nucleotides to the ocular surface and to the internal ocular structures is to soak nucleotides into contact lenses and to allow them to be released slowly. This will reduce the number of times needed to reapply the nucleotide when using it as a pharmacological treatment and also will provide better long-lasting effects.
Acknowledgments Supported by SAF2013-44416-R and RETICS RD12/0034/0003.

\section{References}

1. Dominguez-Godinez CO, Martin-Gil A, Carracedo G, GuzmanAranguez A, González-Méijome JM, Pintor J (2013) In vitro and in vivo delivery of the secretagogue diadenosine tetraphosphate from conventional and silicone hydrogel soft contact lenses. J Optom 6(4): 205-211

2. Guzman-Aranguez A, Santano C, Martin-Gil A, Fonseca B, Pintor J (2013) Nucleotides in the eye: focus on functional aspects and therapeutic perspectives. J Pharmacol Exp Ther 345(3):331-341

3. Lau OC, Samarawickrama C, Skalicky SE (2014) P2Y2 receptor agonists for the treatment of dry eye disease: a review. Clin Ophthalmol 30(8):327-334

4. http://www.santen.com/en/news/20101213.pdf

5. Guzman-Aranguez A, Colligris B, Pintor J (2013) Contact lenses: promising devices for ocular drug delivery. J Ocul Pharmacol Ther 29(2):189-199 